\title{
AVALIAÇÃO SENSORIAL DE ABACAXI "PÉROLA" (ANANAS COMOSUS L.) MINIMAMENTE PROCESSADO EM FORMA DE CUBO, TRATADO COM ÁCIDO CÍTRICO
}

\author{
SENSORY EVALUATION OF "PEARL" PINEAPPLE (ANANAS COMOSUS L.) \\ MINIMALLY PROCESSED CUBE-SHAPED, TREATED WITH CITRIC ACID
}

\author{
Juliana Audi Giannoni ${ }^{1}$ \\ Kely Braga Imamura ${ }^{2}$ \\ Eduardo Luís Silva Rojo ${ }^{3}$ \\ Gisele Nogueira Faria Rojo ${ }^{4}$
}

RESUMO: O processamento mínimo de vegetais é definido como a operação que elimina as partes não comestíveis destes, como cascas, talos e sementes, oferecendo produtos similares ao in natura, deixando estes alimentos prontos para o consumo, sem a perda da condição de produto fresco com qualidade. Objetivou-se com este estudo a elaboração do abacaxi, da cultivar Pérola (Ananas comosus L.), minimamente processado em forma de cubos, tratados com solução de ácido cítrico a $4 \%$ por 2 minutos e armazenados a $4{ }^{\circ} \mathrm{C}$, visando facilitar seu consumo e verificar sua aceitação sensorial junto aos consumidores. Para a realização do processamento mínimo, os abacaxis passaram pelas etapas de seleção, lavagem, sanificação no fruto inteiro, corte das extremidades, fatiamento, retirada dos cubos, sanificação nos cubos, tratamento, drenagem, embalagem e armazenamento. Em seguida foram realizadas análises físicas, químicas, microbiológicas e sensoriais, no abacaxi

\footnotetext{
I Pós-Doutorado em Ciência dos Alimentos com Irradiação Gama e Processamento Mínimo pela Universidade Federal de Lavras (UFLA), Lavras/MG. Doutorado e Mestrado em Agronomia/Horticultura pela Universidade Estadual Paulista "Júlio de Mesquita Filho" Campus Botucatu-SP. Graduação em Agronomia pela Universidade Federal de Lavras (UFLA), Lavras/MG. Professora Associado III, junto ao curso de Tecnologia em Alimentos e da Pós-Graduação da Fatec/Marília/SP. Experiência na área de Ciência e Tecnologia de Alimentos, atuando principalmente nos seguintes temas: Toxicologia, Processamento mínimo, Irradiação Gama, Análise sensorial, Tecnologia de Açúcar e Álcool; e na área de Horticultura com PANCs. E-mail: audigiannoni@gmail.com.

${ }^{2}$ Doutora e Mestre em Biotecnologia pela Unesp-Araraquara, com ênfase em biologia molecular e micro-organismos, Especialista em Microbiologia (Lato sensu) pela Universidade do Oeste Paulista (UNOESTE), e Tecnóloga em Alimentos pela Faculdade Estadual de Tecnologia de Marília (FATEC-MARILIA). 5 anos de experiência em Indústria de Alimentos, como chefe laboratorista Industrial. Coordenadora, Professora e Orientadora pela Unyleya em cursos da área de engenharia de alimentos, desenvolvimento de novos produtos, análises clínicas e microbiologia. Experiência na área de Ciência, Engenharia e Tecnologia de Alimentos, Produção Industrial, Química e Microbiologia. E-mail: kely.imamura@hotmail.com.

${ }^{3}$ Graduado em Tecnologia em Alimentos pela FATEC/Marília/SP e Engenharia de Produção pela Fundação Eurípedes Soares da Rocha - UNIVEM - Marília/SP. Formação na ferramenta Lean Manufacturing em Green Belt Seis Sigma pela RL Associados, São Bernardo do Campo/SP. Experiência na área fabril com atuação em elaboração de Procedimentos Operacionais Padronizados (POP); Geração e acompanhamento de Indicadores fabris, tais como OEE, Indisponibilidade de máquinas, Qualidade dos produto e tempo de Setup; Participação em time de 5 S; Aplicação de ferramentas de análise e qualidade tais como Ciclo PDCA, Diagrama de Paretto, Diagrama de Ishikawa, Ferramenta $\mathrm{A}_{3}$; Elaboração de Planos de Ação mediante análise de processos, na Spiltag Industria de Transformações Plásticas, Marília/SP; Experiência em Planejamento Programação e Controle de Produção, na Máquinas Agrícolas Jacto, Pompéia/SP, com atuação em controle de estoque de itens de fixação, usinados e adesivos. Atuação em Time de Sucesso do Cliente, na Yapay Pagamentos Online Marília/SP, setor estratégico que atua na retenção, consolidação e acompanhamento de empresas de vendas online (E-commerces). Email: eduardolsrojo@hotmail.com.

${ }^{4}$ Graduada em Tecnologia em Alimentos pela FATEC/Marília/SP e Administração de Empresas pela Fundação Eurípedes Soares da Rocha - UNIVEM - Marília/SP. Formação na ferramenta Lean Manufacturing em Green Belt Seis Sigma pela RL Associados, São Bernardo do Campo/SP. Experiência em processos internos na Receita Federal de Marília/SP; Setor de Comércio Exterior na Máquinas Agrícolas Jacto Pompéia/SP, com atuação em processos de importação de materiais utilizados para montagem de máquinas e equipamentos agrícolas, efetuando o acompanhamento junto a fornecedores, transportadores, agentes de cargas e despachantes aduaneiros. E-mail: giselefariagı@hotmail.com
} 
pérola minimamente processado ao longo dos sete dias de armazenamento. As análises microbiológicas apresentaram valores de $200 \mathrm{UFC} / \mathrm{g}$ de coliformes totais para os abacaxis sem tratamento e inibição total para os tratados com ácido cítrico a $4 \% / 2$ '. Os dados da análise sensorial permitiram verificar que, a aparência, cor, sabor e textura das amostras, não obtiveram diferenças significativas entre a amostra tratada e não-tratada, sendo aceitas pelos consumidores. Sendo assim, o tratamento do abacaxi minimamente processado com ácido cítrico pode ser utilizado como etapa da elaboração de fresh-cut sem influenciar a aceitação sensorial dos consumidores.

Palavras-chave: Qualidade. Micro-organismos. Alimentos. Segurança. Tecnologia

ABSTRACT: The minimum vegetable processing is defined as the operation that eliminates the non-edible parts of these, such as shells, stems and seeds, offering similar products, natural leaving these foods ready for consumption without the loss of the fresh product condition with quality. The objective of this study the elaboration of pearl pineapple (Ananas comosus L.) minimally processed in the form of cubes, treated with citric acid solution to $4 \%$ and stored at $4{ }^{\circ} \mathrm{C}$ in order to facilitate their consumption and verify their sensory acceptance among consumers. For the realization of minimal processing, pineapples gone through the stages of selection, washing, sanitizing the whole fruit, cut the extremities, slicing, withdrawal of cubes, the cubes sanitation, treatment, drainage, packaging and storage. Then were performed analyzes physical, chemical, microbiological and sensory, the pearl pineapple minimally processed over the seven days of storage. Microbiological analyzes gave values of $200 \mathrm{CFU} / \mathrm{g}$ of total coliforms pineapples for untreated and complete inhibition to treated with citric acid (4\%). Data from the sensory analysis allowed that the appearance, color, taste and texture of the samples, did not obtain significant differences, between treated and untreated sample, being accepted by consumers. Thus, treatment of minimally processed pineapple with citric acid can be used as step of preparing fresh-cut without influencing consumer acceptance.

Keywords: Quality. Microrganisms. Security. Food. Technology

\section{INTRODUÇÃO}

Nos últimos anos, a indústria de alimentos tem passado por constantes mudanças para se adaptar às crescentes exigências dos consumidores, que estão buscando cada vez mais alimentos saudáveis (HEIFFIG, AGUILA, KLUGE, 2006). Segundo a International FreshCut Producers Association, produtos minimamente processados são definidos como qualquer fruta ou hortaliça, ou ainda qualquer combinação delas, que foi alterada fisicamente a partir de sua forma original, embora mantenha o seu estado fresco. Independentemente do tipo, ele é selecionado, lavado, descascado e cortado, e posteriormente, é embalado ou préembalado (IFPA, 2021).

Fatores como as significativas mudanças nos hábitos alimentares dos consumidores, a maior participação da mulher no mercado de trabalho, a diminuição no número de indivíduos por família, o maior número de pessoas morando sozinhas e o aumento do setor de refeições coletivas, têm impulsionado o mercado de produtos minimamente processados (MORETTI, 2007). Além de apresentar as frutas e hortaliças de uma forma mais conveniente, o processamento mínimo de vegetais possibilita maior praticidade e economia de tempo no preparo diário dos alimentos, cada vez mais necessários ao agitado mundo 
moderno (ALVES, et al., 2010).

O manuseio excessivo durante o preparo dos minimamente processados, as condições higiênico-sanitárias do manipulador, dos equipamentos, utensílios e do ambiente influenciam na qualidade microbiológica do produto final, nas alterações sensoriais do produto durante sua vida de prateleira e aumentam os riscos de contaminação por microorganismos deteriorantes e patogênicos (FANTUSI, PUSCHMANN, VANETTI, 2004; VANETTI, 2004). As etapas do processamento mínimo, como o fracionamento, descasque, retirada de sementes, talos, podem causar injúrias aos vegetais. Estas injúrias induzem respostas bioquímicas e fisiológicas, como o aceleramento do metabolismo e escurecimento do vegetal contribuindo para a perda de qualidade do produto, afetando, consequentemente, sua vida útil (BONNAS, et al., 2003; BRACKETT, 1997).

O escurecimento enzimático de frutas e hortaliças inicia-se em resposta a estas injúrias físicas e fisiológicas tendo como resultado, a aceleração da oxidação de compostos fenólicos, gerando polímeros de coloração escura. A velocidade dessa reação pode ser controlada pela utilização de agentes oxidantes, diminuição da temperatura ou $\mathrm{pH}$ (BRACKETT, 1997). Neste sentido, para prolongar a vida de prateleira dos alimentos minimamente processados, o uso de aditivos, conhecidos como antioxidantes têm sido cada vez mais necessários. Uma gama de antioxidantes estão disponíveis no mercado, entretanto, entre os antioxidantes mais utilizados encontram-se o ácido benzóico, ácido p-cumárico, ácido ascórbico, tocoferóis, ácido cafeico, ácido cítrico e o ácido fosfórico (Dos SANTOS, 2009). A aplicação de inibidores de escurecimento em alimentos minimamente processados deve ser restrito aos compostos não tóxicos e que não alterem o aroma e sabor do alimento. Alguns compostos naturais como o ácido cítrico e ácido ascórbico tem apresentado efeito positivo na manutenção, na qualidade e no aumento da vida de prateleira de produtos minimamente processados (FIGUEIREDO, et al., 2005). Além de antioxidante, o ácido cítrico é também um agente quelante e pode ser utilizado sinergicamente com o ácido ascórbico com o intuito de inativar enzimas como a polifenoloxidaese que causa reações de escurecimento nas frutas e diminuir a carga microbiana, auxiliando para a manutenção da qualidade e aumento da vida de prateleira de frutos minimamente processados. $\mathrm{O}$ ácido cítrico atua diminuindo o $\mathrm{pH}$ do meio, tornando este inapropriado para a ação de enzimas responsáveis pelo escurecimento do vegetal. Os efeitos do ácido cítrico frente à inibição do escurecimento enzimático têm sido testados por vários pesquisadores (Dos SANTOS, 2009; FIGUEIREDO, et al., 2005).

Dentre os frutos comercializados minimamente processados, o abacaxi apresenta um grande potencial, devido às suas características organolépticas e aceitação no mercado consumidor. Segundo Santos et al., (2005), o abacaxi (Ananas comosus L.) é considerado um dos frutos tropicais mais importantes, cuja comercialização vem se expandindo no mercado mundial, principalmente por suas apreciáveis características de sabor, aroma e cor. No entanto este fruto é classificado como inconveniente, por ser de difícil consumo, devido à dificuldade de retirar sua casca áspera e espinhosa. Diante deste fato, o processamento mínimo soluciona esta questão por elaborar produtos com tamanhos reduzidos, fatiados, sem casca, sem sementes e de fácil consumo.

A mudança de hábito do consumidor, com tendências ao uso de produtos mais convenientes, saudáveis e seguros, tem orientado o setor de alimentos na busca por produtos novos e atrativos (BONNAS, et al., 2003). Neste contexto, este estudo teve por objetivo a elaboração do abacaxi minimamente processado em forma de cubos, tratados com solução a $4 \%$ de ácido cítrico; visando facilitar seu consumo e verificar sua aceitação sensorial junto 
aos consumidores.

\section{Métodos}

\section{Aquisição da matéria-prima}

Os abacaxis da cultivar Pérola (Ananas comosus L.) foram adquiridos no comércio local da cidade de Marília/SP, e transportados para o Laboratório de Processamento da FatecMarília/SP, para a elaboração dos cubos minimamente processados.

\section{Etapas de processamento mínimo do abacaxi "Pérola"}

Após a colheita, os frutos foram transportados e manuseados com cuidado rapidamente para o local de processamento. Esta recepção ocorreu em local apropriado, onde o material impróprio foi descartado. A matéria-prima apresentava excelente qualidade, sendo selecionadas quanto ao ponto de maturação e à ausência de deterioração e/ou danos mecânicos. Todas as etapas do processamento mínimo foram realizadas em condições higiênico-sanitárias adequadas, além destes cuidados, os manipuladores usaram equipamentos de proteção individual como: touca, máscara, luvas, avental de manga longa e protetor para os pés. Os abacaxis foram devidamente higienizados, bem como todos os materiais utilizados.

Os frutos inteiros foram devidamente lavados em água corrente limpa e de boa qualidade, usando-se escova e detergente neutro, com o intuito de remover as sujidades e micro-organismos aderidos à superfície do produto. Retirou-se manualmente a coroa do abacaxi a fim de evitar algum tipo de contaminação. Os abacaxis foram imersos em solução sanificante de hipoclorito de sódio a 2,5\%, na concentração de 200mg.L-I/20" para a remoção de micro-organismos.

Foram retiradas as extremidades dos frutos para padronizar as fatias em aproximadamente três centímetros. Já com as fatias prontas e sem cascas elaboraram-se os cubos de aproximadamente dois centímetros. Todos os cortes foram realizados com facas afiadas de aço inox, devidamente higienizadas. Os cubos de abacaxi minimamente processados foram imersos em solução sanificante de hipoclorito de sódio Iomg.L-I/ıo" para a eliminação de possíveis contaminantes durante o corte (Figura I).

Foi usado como conservante natural do produto minimamente processado, o ácido cítrico, com a finalidade de promover vida maior útil, bem como manter sua qualidade. Para isto, os cubos de abacaxi foram imersos em solução de ácido cítrico a $4 \%$ por 2 minutos, após a imersão, o produto já processado foi colocado em papel toalha a fim de retirar o excesso de líquido acumulado na superfície do produto (Figura I). O produto foi acondicionado em embalagens plásticas Galvanotek ${ }^{\circledR}$ PET transparentes, rígidas com tampa encaixável e as embalagens foram armazenadas a temperatura de $4^{\circ} \mathrm{C}$ por 7 dias. 
Figura I- Fluxograma do processamento mínimo do abacaxi.

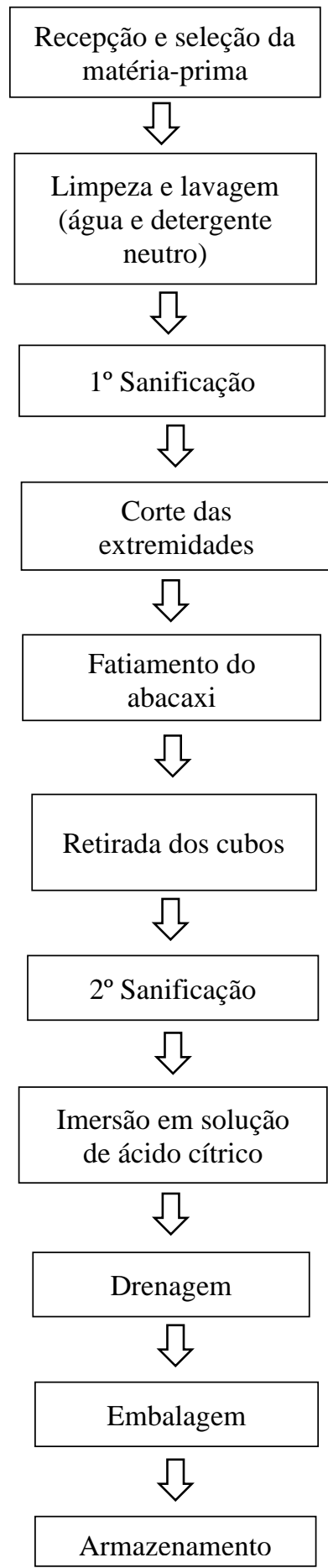

Fonte: Dados dos autores, (2021). 


\section{Análises Realizadas}

Para a caracterização física e química foram realizadas as análises de aparência, $\mathrm{pH}$, acidez titulável e sólidos solúveis. Todas as análises foram realizadas em triplicata e todas estas análises seguiram o recomendado no Manual e Métodos Físicos e Químicos para Análise de Alimentos (INSTITUTO ADOLFO LUTZ, I985). As análises físicas e químicas foram realizadas no Laboratório de Físico-Química da FATEC/Marília/SP. Para as análises sensoriais, utilizou-se o método afetivo de aceitação utilizando a escala hedônica de 9 pontos e a intenção de compra foi avaliada utilizando uma escala hedônica de 5 pontos. Ao longo do tempo de armazenamento foram avaliados também os atributos: Aparência: atribuiu-se notas de 3 (produto bom) 2 (produto razoável) e I (produto ruim ou impróprio), segundo Instituto Adolfo Lutz, (1985). As análises microbiológicas foram realizadas no Laboratório de Microbiologia da FATEC/Marília/SP, seguindo os métodos descritos por SILVA et al., (2010). O CAAE está sob o número: 25997219.1.0ooo.8ı20.

\section{Análises Físicas e Químicas}

O experimento foi avaliado nos tempos o (primeiro dia), 2 (terceiro dia), 4 (quinto dia) e 6 (sétimo dia) ao longo dos 7 dias de armazenamento. Para as análises físicas e químicas foram avaliados valores de $\mathrm{pH}$ : onde foi determinado por potenciômetria, através da leitura da amostra em pHmetro à temperatura de $25^{\circ} \mathrm{C}$; acidez titulável: baseia-se na neutralização dos ácidos presentes na amostra com titulação simples utilizando solução de hidróxido de sódio $(\mathrm{o}, \mathrm{IN})$; sólidos solúveis ( $\left.{ }^{\circ} \mathrm{Brix}\right)$ : leitura da amostra em refratômetro de mão; perda de peso através da pesagem das embalagens contendo os cubos de abacaxi minimamente processado durante o período de armazenamento destes.

\section{Análises Microbiológicas}

Para as análises microbiológicas, foi utilizado o método de plaqueamento em superfície, onde foi analisada a presença ou ausência de Salmonella spp. como também determinado a quantidade de coliformes totais e termotolerantes presente na amostra. Estas análises foram realizadas no (tempo o) primeiro dia e no (tempo 6) sétimo dia. No (tempo o), os cubos de abacaxi minimamente processados foram analisados isentos dos tratamentos com ácido cítrico e hipoclorito de sódio. A análise microbiológica do (tempo 6) foi realizada nos frutos minimamente processados tratados com solução de ácido cítrico a 4\%/2' e sanificados com solução de hipoclorito de sódio a ıoppm/ı”".

\section{Análise de Coliformes Totais e Termotolerantes}

Em ambiente asséptico, após homogeneização do fruto, $25 \mathrm{~g}$ da amostra foi transferida para $225 \mathrm{~mL}$ de água peptonada tamponada e, a partir desta, foram preparadas diluições até $\mathrm{IO}^{-3}$. As amostras foram inoculadas em tubos contendo Caldo Lauril Sulfato Triptose (LST), os tubos foram incubados a $35-37^{\circ} \mathrm{C} / 24-48 \mathrm{~h}$. A partir dos tubos de LST que apresentaram produção de gás, foi transferida uma alçada de cada cultura para os tubos contendo Caldo Verde Brilhante Bile 2\% (VB) e Caldo Escherichia coli (EC). Os tubos de VB seguiram para incubação a $35-37^{\circ} \mathrm{C} / 24-48 \mathrm{~h}$, e os tubos de EC seguiram para incubação a $44-45^{\circ} \mathrm{C} / 24-48 \mathrm{~h}$. Após o tempo de incubação, os tubos de VB com crescimento e formação de gás foram 
confirmativos para a presença de coliformes totais. Para a contagem de Escherichia coli spp., de cada tubo de Caldo EC com crescimento foi retirada uma alçada, esta alçada foi estriada em placas de meio Ágar Levine Eosina Azul de Metileno (L-EMB). As placas seguiram para inoculação a $35^{\circ} \mathrm{C} / 24 \mathrm{~h}$. As colônias típicas (nucleadas com centro preto, com ou sem brilho metálico) foram estriadas em tubos com meio Ágar Padrão para Contagem (PCA) e incubadas a $35^{\circ} \mathrm{C} / 24 \mathrm{~h}$. Os tubos PCA com crescimento de culturas puras foram transferidos para a série bioquímica Rugai com Lisina incubada a $35^{\circ} \mathrm{C} / 24 \mathrm{~h}$. A confirmação de E. coli foi obtida através dos resultados da série bioquímica.

\section{Análise de Salmonella spp.}

Assepticamente, após homogeneização dos vegetais, $25 \mathrm{~g}$ da amostra foi transferida para $225 \mathrm{~mL}$ de água peptonada tamponada que seguiu para incubação a $37^{\circ} \mathrm{C} / \mathrm{I} 8 \mathrm{~h}$. A partir desta, foram preparadas diluições até $1^{-3}$. As diluições foram transferidas para tubos contendo Caldo Tetrationato Muller Kauffmann Novobiocina (MKTTn) e tubos com Caldo Selenito-Cistina (SC), que seguiram para incubação a $37^{\circ} \mathrm{C} / 24 \mathrm{~h}$. De cada cultura foi estriada uma alçada para os meios diferenciais Ágar Xilose Lisina Desoxicolato (XLD), Ágar Bismuto Sulfito (BS) e Salmonella Shigella Ágar (SSA) seguidos de incubação em placas invertidas a $37^{\circ} \mathrm{C} / 24 \mathrm{~h}$. Com a detecção das colônias típicas, foi estriada uma alçada destas colônias e transferida para placas com meio Ágar Nutriente (NA). As placas foram incubadas invertidas a $37^{\circ} \mathrm{C} / 24 \mathrm{~h}$. Após a incubação, foram selecionadas colônias isoladas para os testes de confirmação. A confirmação de Salmonella spp. foi obtida por meio do teste de série bioquímica Rugai com Lisina.

\section{Análises Sensoriais}

A avaliação sensorial foi feita com 50 pessoas, não treinadas, de ambos os sexos, sendo distribuídos dois cubos de abacaxi minimamente processado, para cada provador, em copos plásticos numerados com três dígitos. $O$ teste sensorial aplicado foi o afetivo de aceitação, utilizando a escala hedônica de 9 pontos, variando de I a 9, do desgostei extremamente ao gostei extremamente. $\mathrm{Na}$ mesma ficha sensorial avaliou-se a intenção de compra por parte do consumidor, usando uma escala de notas de i a 5 , certamente não compraria ao certamente compraria, respectivamente. Foi calculado o Índice de Aceitabilidade (IA) para verificar a porcentagem da intenção de compra do produto por parte dos consumidores. Este índice baseia-se na regra de três simples, onde: Nota máxima $=100 \%$. IA $=(A * 100) / B$, sendo $A=$ média obtida e $B$ = nota mais alta obtida na escala hedônica (DZAZIO, et al., 2007).

\section{Análise Estatística}

Para as análises sensoriais utilizou-se o Teste T de Student, e a análise de Variância (ANOVA) complementada com o Teste de Tukey, e com o Teste de Qui-quadrado. Os dados de todas as outras análises foram expressos por meio de média, desvio-padrão e submetidos à análise de variância utilizando ANOVA e Tukey, empregando-se o programa computacional BioEstat (AYRES, et al., 2007). 


\section{Resultados e discussão}

No primeiro dia de armazenamento (tempo o), os valores de $\mathrm{pH}$ se encontraram maior que os demais dias (Tabela I), pois a caracterização da matéria-prima foi realizada sem o ácido cítrico e o hipoclorito de sódio. As etapas de sanitizações com hipoclorito de sódio são essenciais para a manutenção da qualidade microbiológica de alimentos minimamente processados. Na resolução RDC-77/or, a ANVISA estabelece os limites máximos de cloro ativo para produtos formulados a base de hipoclorito de sódio e sua utilização em hortifrutícolas, o teor de cloro ativo deve ser no máximo de $2,5 \%$ ou $200 \mathrm{mg} / \mathrm{L}$ para o seu uso em frutas e hortaliças.

De acordo com Andrade (1999) e Thé (2001) os valores de pH, em abacaxis, oscilam entre 3,5 e 4,o, faixa esta que se enquadra nos valores encontrados neste estudo. Os tempos com tratamento ácido tiveram uma queda no $\mathrm{pH}$ conforme o esperado. Santos et al., (2005) também registraram valores semelhantes, com média de 3,6 para abacaxi "Pérola" minimamente processado, armazenado a $4^{\circ} \mathrm{C}$ durante ro dias.

Tabela r. Valores obtidos para $\mathrm{pH}$ do abacaxi minimamente processado avaliado durante 7 dias a $4^{\circ} \mathrm{C}$.

\begin{tabular}{ccccc}
\hline Dias & 0 & 2 & 4 & 6 \\
\hline \multirow{2}{*}{$\mathrm{pH}$} & $3,68 \pm 0,02$ & $3,29 \pm 0,06$ & $3,21 \pm 0,02$ & $3,20 \pm 0,04$ \\
& $\mathrm{C}$ & $\mathrm{A}$ & $\mathrm{A}$ & $\mathrm{A}$ \\
\hline
\end{tabular}

Médias seguidas de mesma letra não diferem entre si.

$*_{0}, 2,4$ e 6; referente aos tempos de armazenamento.

A acidez titulável representa a somatória dos ácidos orgânicos livres e complexados dos frutos, expresso em porcentagem do ácido predominante. Esse valor aumenta durante o crescimento do fruto até seu completo desenvolvimento fisiológico, quando então começa a diminuir conforme amadurece (MODA, et al., 2008).

Como demonstra a Tabela 2, os valores de acidez variaram de $0,59 \%$ a $0,84 \%$, os tempos 2, 4 e 6 apresentaram maiores valores de acidez devido ao tratamento com ácido cítrico no abacaxi. Entretanto, em todas estas amostras, a acidez permaneceu abaixo de $1 \%$ de ácido cítrico, isto indica, de acordo com Antoniolli et al., (200o), que não há restrição ao consumo do abacaxi minimamente processado sob este parâmetro. Santos et al., (2005) também observaram o aumento da acidez titulável em abacaxi "Pérola" minimamente processada e armazenado a $5^{\circ} \mathrm{C}$, com valores médios de o,53 a o,66\%. Já Figueiredo, Queiroz e Noronha, (2003) constataram redução de 0,45 para $0,36 \%$ na acidez de abacaxi "Smooth Cayenne" minimamente processado estocado a $5^{\circ} \mathrm{C}$. 
Tabela 2. Valores obtidos para acidez titulável de abacaxi minimamente processado avaliados durante 7 dias armazenados a $4^{\circ} \mathrm{C}$.

\begin{tabular}{ccccc}
\hline Dias & 0 & 2 & 4 & 6 \\
\hline Acidez & $0,5904 \pm$ & o,o157 & o,8147 \pm & o,ol12 \\
Titulável & A & B & B & B \\
\hline
\end{tabular}

(I) Médias seguidas de mesma letra não diferem entre si.

$*_{0}, 2,4$ e 6; referente aos tempos de armazenamento.

Neste estudo, verificou-se que a concentração de sólidos solúveis totais foi diminuindo conforme o tempo de armazenamento (Tabela 3 ).

Tabela 3. Valores obtidos para sólidos solúveis de abacaxi minimamente processado avaliados durante 7 dias armazenados $4^{\circ} \mathrm{C}$.

\begin{tabular}{ccccc}
\hline Dias & 0 & 2 & 4 & 6 \\
\hline Acidez & I3,00 $\pm 0,00$ & I2,00 $\pm 0,00$ & II,50 $\pm 0,00$ & II,08 $\pm 0,14$ \\
Titulável & D & B & A & C \\
\hline
\end{tabular}

(I) Médias seguidas de mesma letra não diferem entre si.

$*_{0}, 2,4$ e 6; referente aos tempos de armazenamento.

A diminuição de sólidos solúveis no abacaxi minimamente processado aconteceu possivelmente devido à ação do ácido cítrico que promoveu aumento na acidez mascarando os açúcares presentes na amostra. Valores semelhantes foram encontrados por Antoniolli et al., (2000) que observaram de I0,I a 13,4\% de sólidos solúveis ao analisarem diferentes partes de abacaxi minimamente processado. Já Chaves et al., (20II) ao analisarem abacaxi "Pérola" minimamente processado, tratado com solução de ácido cítrico a $2 \%$, verificaram valores de 7 a $14{ }^{\circ}$ Brix.

Bonnas et al., (2003), afirmaram que a variação da concentração de sólidos solúveis pode ser atribuída ao grau de amadurecimento do abacaxi, que, normalmente é definido pela coloração da casca, que é um indicador que pode ser influenciado por outros fatores, tais como clima e tamanho dos frutos. Pequenas variações também foram observadas por Sarzi e Durigan, (2002), que verificaram valores de 12 a $14^{\circ}$ Brix. De acordo com Cenci, (2011), baixas temperaturas são capazes de diminuir o metabolismo dos vegetais, como também de reduzir sua respiração e, consequentemente, o consumo energético.

A perda de massa é um dos principais fatores que limitam a vida útil dos produtos hortícolas, sendo relacionada à perda de água, que é a causa principal da deterioração. Além de resultar em perdas quantitativas, a perda de massa também prejudica a aparência, a textura e a qualidade nutricional. A taxa de transpiração é influenciada por fatores internos como características morfológicas, relação entre superfície e volume e estágio de maturação, além de fatores externos como temperatura, movimento de ar e pressão atmosférica 
(CHAVES, et al., 20II). No período de armazenamento, observou-se que não houve variação significativa no peso das amostras (p<0,05). Já Silva et al., (2003) encontraram valor de 3,13\% de perda de massa em abacaxi minimamente processado tratado com 20oppm de cloro ativo por 2 minutos, armazenado a $5^{\circ} \mathrm{C}$ por 16 dias. Prado et al., (200o) avaliando a influência do hipoclorito de sódio na qualidade de abacaxis da variedade Pérola minimamente processados cortados em leque armazenados a $8^{\circ} \mathrm{C}$ por 9 dias, verificaram que estes cortes apresentaram maior índice de líquidos drenados ao longo do tempo de armazenamento, o que indica maior perda de peso.

Neste estudo, não houve perda de massa, provavelmente devido à interação entre a baixa temperatura de estocagem com o ácido cítrico, que podem ter auxiliado na manutenção da integridade das células, diminuindo o metabolismo do fruto resultando em menor respiração e transpiração (CENCI, 20II).

Tratamentos químicos contendo um acidulante, geralmente o ácido cítrico, são usados para prevenir o escurecimento, uma vez que abaixam o $\mathrm{pH}$, inibindo a atividade da enzima polifenoloxidase (CHAVES, et al., 20II). De acordo com Araújo (20II) a diminuição do $\mathrm{pH}$ do tecido reduz a velocidade da reação de escurecimento, pois o $\mathrm{pH}$ ótimo das polifenoloxidases está entre 6,o e 7,o. Neste estudo, os valores encontrados após o tratamento ácido do abacaxi estavam bem abaixo do $\mathrm{pH}$ ótimo destas enzimas (Tabela $\mathrm{s}$ ). $\mathrm{O}$ abacaxi, naturalmente já tem um $\mathrm{pH}$ baixo, o tratamento ácido intensifica essa acidez, o que auxilia na manutenção da cor do fruto durante o tempo de armazenamento. Verificou-se que ao longo do armazenamento, não houve variação visível da cor do abacaxi minimamente processado.

Ao avaliar a contaminação microbiológica do abacaxi minimamente processado, verificou-se que, no primeiro dia de análise (tempo o) foi encontrado 200 Unidades Formadoras de Colônia (UFC/g) de Coliformes totais, bem como ausência tanto de Salmonella spp. quanto de Coliformes termotolerantes. No último dia de armazenamento (tempo 6) verificou-se a ausência de Coliformes totais, termotolerantes e Salmonella spp.

No tempo 6, os cubos de abacaxi minimamente processados foram tratados com solução a $4 \%$ de ácido cítrico por 2 min e sanificados com hipoclorito de sódio a Ioppm/ıo" Sendo assim, verificou-se que estes tratamentos foram capazes de inibir estes microorganismos. A sanificação com produtos à base de cloro é amplamente recomendada para inibir o crescimento microbiológico em frutas e hortaliças minimamente processadas (BEUCHAT, 1992; BEUCHAT, BRACKETT, 1990). Antoniolli et al., (2005), ao analisarem as características microbiológicas de abacaxi minimamente processado, detectaram ausência de coliformes termotolerantes e baixas contagens de coliformes totais, semelhantes ao encontrado neste estudo.

No Brasil, a Resolução RDC № 331, de 23 de dezembro de 2019, do Ministério da Saúde (BRASIL, 2019) estabelece os padrões microbiológicos sanitários para alimentos. Nesta resolução, não existe padrões específicos para as frutas e hortaliças minimamente processadas. Sendo assim, os minimamente podem ser inseridos no grupo de alimentos designados como: "alimentos frescos, in natura, preparados (descascados ou selecionados ou fracionados), sanificados, refrigerados ou congelados, para consumo direto”. Dessa forma, a 
implantação das Boas Práticas de Fabricação (BPF) e de um programa de Análise de Perigos e Pontos Críticos de Controle (APPCC) é essencial para prevenir e controlar os riscos da contaminação microbiana e manter a qualidade do produto (CHITARRA, 200I).

Fatores como baixa temperatura $\left(4^{\circ} \mathrm{C}\right)$, adição de ácido cítrico e tratamento com hipoclorito de sódio, foram capazes de inibir tanto a ação de enzimas que causam escurecimento, quanto ao desenvolvimento de micro-organismos deteriorantes, durante o período de conservação.

Os dados da análise sensorial permitiram verificar que, a aparência, cor, sabor e textura das amostras, não obtiveram diferenças significativas, ou seja, a aceitação do consumidor (homens e mulheres) foi grande tanto para o produto sem tratamento algum quanto para aquele submetido a tratamento com hipoclorito de sódio e ácido cítrico, armazenado por sete dias a $4^{\circ} \mathrm{C}$ (Tabela 4$)$.

Tabela 4. Valores obtidos para análise sensorial de abacaxi minimamente processado avaliados durante 7 dias armazenados $4^{\circ} \mathrm{C}$.

\begin{tabular}{|c|c|c|c|c|}
\hline & Feminino & Masculino & Feminino & Masculino \\
\hline Aparência & $\begin{array}{c}8,18 \pm 0,87 \\
\mathrm{~A}^{\mathrm{I}} \mathrm{a}^{2}\end{array}$ & $\begin{array}{c}8,20 \pm 0,4 \mathrm{I} \\
\mathrm{Aa}\end{array}$ & $\begin{array}{c}8,00 \pm 0,70 \\
\mathrm{Aa}\end{array}$ & $\begin{array}{c}7,67 \pm 1,23 \\
\mathrm{Ba}\end{array}$ \\
\hline Cor & $\begin{array}{c}8,06 \pm 0,92 \\
\mathrm{Aa}\end{array}$ & $\begin{array}{c}8,00 \pm 0,65 \\
\mathrm{Aa}\end{array}$ & $\begin{array}{c}7,87 \pm 0,84 \\
\mathrm{Aa}\end{array}$ & $\begin{array}{c}8,00 \pm 0,74 \\
\mathrm{Aa}\end{array}$ \\
\hline Sabor & $\begin{array}{c}7,82 \pm \mathrm{I}, 06 \\
\mathrm{Aa}\end{array}$ & $\begin{array}{c}7,80 \pm \mathrm{I}, \mathrm{OI} \\
\mathrm{Aa}\end{array}$ & $\begin{array}{c}7,84 \pm \mathrm{I}, 05 \\
\mathrm{Aa}\end{array}$ & $\begin{array}{c}7,67 \pm \mathrm{I}, 02 \\
\mathrm{Aa}\end{array}$ \\
\hline Textura & $\begin{array}{c}8,35 \pm 0,65 \\
\mathrm{Aa}\end{array}$ & $\begin{array}{c}8,07 \pm 0,70 \\
\mathrm{Aa}\end{array}$ & $\begin{array}{c}8, \mathrm{II} \pm \mathrm{o}, 83 \\
\mathrm{Aa}\end{array}$ & $\begin{array}{c}7,83 \pm \mathrm{I}, 022 \\
\mathrm{Aa}\end{array}$ \\
\hline Int. compra & $\begin{array}{c}4,44 \pm 0,6 \mathrm{I} \\
\mathrm{Aa}\end{array}$ & $\begin{array}{c}4,13 \pm 0,64 \\
\mathrm{Aa}\end{array}$ & $\begin{array}{c}4,45 \pm 0,60 \\
\mathrm{Aa}\end{array}$ & $\begin{array}{c}4,00 \pm 0,74 \\
\mathrm{Ba}\end{array}$ \\
\hline
\end{tabular}

(I) Médias seguidas de mesma letra maiúscula não diferem entre si na comparação de sexo, fixado o momento.

(2) Médias seguidas de mesma letra minúscula não diferem entre si na comparação de momento, fixado o sexo.

* I e 7; referente ao tempo de armazenamento e dias de análise sensorial

No período armazenado não houve alterações sensoriais sendo assim, a imersão em solução de hipoclorito de sódio Ioppm/I" e o tratamento com solução de ácido cítrico a 4\%/2', foram capazes de manter as características sensoriais do abacaxi minimamente processado, indicando que o mesmo se encontrou em condições sensoriais adequadas para o consumo. Chaves et al., (20II), ao tratarem abacaxi "Pérola" com ácido cítrico e ácido ascórbico sob refrigeração de 5 e $10^{\circ} \mathrm{C}$, verificaram que não houve variações visuais e sensoriais do produto durante o período de armazenamento de 4 dias.

O Índice de Aceitabilidade (IA) no primeiro dia de armazenamento foi de $88,8 \%$ para as mulheres, e $82,6 \%$ para os homens. No sétimo dia de armazenamento o IA foi de $89 \%$ para mulheres, e $80 \%$ para os homens, onde a média entre homens e mulheres foi de $84,5 \%$. Dzazio et al. (2007) e Teixeira et al., (1987) afirmam que para um produto ser aceito é necessário ter aceitabilidade igual ou maior a 70\%. Dessa forma, o abacaxi minimamente processado elaborado neste estudo obteve um ótimo índice de aceitabilidade se apresentando 
apto para comercialização. Os consumidores avaliariam que comprariam o produto apresentando uma intenção de compra de 4,I4 em média (Tabela 4).

\section{CONCLUSÃO}

Nas condições em que este estudo foi realizado, pode-se concluir que a elaboração do abacaxi minimamente processado em forma de cubo tratado com solução a $4 \%$ de ácido cítrico por 2 min e armazenado a $4^{\circ} \mathrm{C}$, culminou em $84,5 \%$ de aceitabilidade, bem como intenção de compra de 4,25 pelos consumidores, vida útil de 7 dias, ausência de Salmonella spp., coliformes totais e termotolerantes. A adição de adição de ácido cítrico e o tratamento com hipoclorito de sódio foram capazes de inibir a ação das enzimas que causam escurecimento em frutos, e o desenvolvimento de micro-organismos deteriorantes, durante o período de conservação.

\section{REFERÊNCIAS}

ALVES, J.A., VILAS-BOAS, E. V. B., VILAS-BOAS, B. M., SOUZA, E.C. Qualidade de produto minimamente processado à base de abóbora, cenoura, chuchu e mandioquinhasalsa. Ciência e Tecnologia de Alimentos, Campinas, v. 30, n. 3, p. 625-634, jul-set, 2010.

ANDRADE, A. P. S. Padrões de identidade e qualidade para o abacaxi, a goiaba e o mamão. Viçosa, 124 p. [Dissertação] (Mestrado em Ciência e Tecnologia de Alimentos) Universidade Federal de Viçosa, 1999.

ANTONiOlli, L. R., BENEDetTi, B. C, CASTRO, P. R. C. Avaliação de algumas características organolépticas de frutos de abacaxizeiro destinados ao processamento mínimo. Congresso Brasileiro de Fruticultura, Fortaleza, 2000.

ANTONIOLli, L. R., BENEDETTI, B. C., FILHO, M. S. M. S., BORGES, M. F. Efeito do hipoclorito de sódio sobre a microbiota de abacaxi 'Pérola' minimamente processado. Revista Brasileira de Fruticultura, Brasília, v. 27, n. I, p.157-ı6o, abr. 2005.

ARAUJO, J. M. A. Química de alimentos: teoria e prática. 5 ed., Viçosa-MG, Ed. UFV, 6oIp. 20II.

AYRES, M., AYRES, Jr. M., AYRES, D. L., SANTOS, A. de A. BioEstat: aplicações estatísticas nas áreas das ciências biológicas e médicas. Belém: Sociedade Civil Mamirauá: MCT-CNPq, 2007.

BEUCHAT, L. R., BRACKETT, R. E. Survival and growth of Listeria monocytogenes on lettuce as influenced by shredding, chlorine treatment, modified atmosphere packaging and temperature. Journal of Food Science, Chicago, v. I, n. 55, p. 755-758, 1990.

BEUCHAT, L. R., Surface desinfection of raw produce. Dairy, Food and Environmental Sanitation. Ames, Iowa, v. I2, n. I, p. 6-9. 1992. 
BONNAS, D. S., CHITARRA, A. B., PRADO, M. E. T., TEIXEIRA-JÚNIOR, D. Qualidade do abacaxi 'Smooth cayenne' minimamente processado. Revista Brasileira de Fruticultura, Cruz das Almas, v. 25, n. 2, p. 206-209, 2003.

BRACKETT, R. E., Alteración microbiológica y microrganismos patógenos de frutas y hortalizas refrigeradas minimamente procesadas. In: Willey, Robert. C. (Ed.). Frutas e hortaliças minimamente processadas e refrigeradas. Zaragoza: Acríbia, p. 263-304, 1997.

BRASIL, Ministério da Saúde, Agência Nacional de Vigilância Sanitária; Resolução RDC № ${ }_{331}$, de 23 de dezembro de 2019.

CENCI, S. A. Processamento mínimo de frutas e hortaliças: tecnologia, qualidade e sistemas de embalagem. Rio de Janeiro: Embrapa Agroindústria de Alimentos, I44p., 20II.

CHAVES, K. F., CRUZ, W. F. da, MARTINS, A. D. de O., SILVA, V. R. O, SILVA, M. H. L., MARTINS, E. M. F. Avaliação físico-química de uva minimamente processada adicionada de ácido ascórbico e de ácido cítrico. Revista Perspectiva online, v. I, n. 2, 20 Ir.

CHAVES, K. F., CRUZ, W. F., SILVA, V. R. O., MARTINS, A. D. O, RAMOS, A. L. S, SILVA, M. H. L. Características físico-químicas e aceitação sensorial de abacaxi 'Pérola' minimamente processado adicionado com antioxidantes. Tecnologia e Ciências Agropecuárias, João Pessoa, v. 5, n. I, p. 35-39, mar. 2011.

CHITARRA, M. I. F. Alimentos minimamente processados. Lavras: FLA/FAEP, $200 I$. Dos SANTOS, I. R. C. Escurecimento enzimático em frutos: polifenoloxidase de atemóia (Annona cherimola Mill. X Annona squamosa L.). [Dissertação] apresentada à Universidade Estadual Paulista "Júlio De Mesquita Filho" UNESP, como parte das exigências do programa de pós-graduação. Araraquara-SP, 2009.

DZAZIO, C. H., MACEDO, D., COSTA, J. A., ANJOS, M. M. Estudo de aceitação sensorial de sorvete de abacaxi pérola com substituição da glucose de milho por mel e aproveitamento do suco da casca na calda. Anais... V Semana de tecnologia de alimentos, Universidade Tecnológica Federal do Paraná, Ponta Grossa, v. 2, n. I, 2007.

FANTUSI, E., PUSCHMANN, R., VANETTI, M. C. D. Microbiota contaminante em repolho minimamente processado. Ciência e Tecnologia de Alimentos, Campinas, v. 24, n. 2, p. 207-2II, abr-jun. 2004 .

FIGUEIREDO, R. M. F., QUEIROZ, A. J. M., NORONHA, M. A. S. Armazenamento de abacaxi minimamente processado tratado com ácido ascórbico. Revista Ciências Exatas e Naturais v. 7, n. I, p. 68-75, 2005.

FIGUEIREDO, R. M. F., QUEIROZ, A. J. M., NORONHA, M. A. S. Armazenamento de abacaxi minimamente processado. Revista Brasileira de Produtos Agroindustriais, n. I, p. 95-103, 2003. 
HEIFFIG, L.S, AGUILA, J.S., KLUGE, R.A. Caracterização físico-química e sensorial de frutos de kiwi minimamente processado armazenados sob refrigeração. Revista Ibero americana de Tecnologia Postcosecha, Hermosillo, México, v. 8, n. I, p.26-32, 2006.

IFPA. International fresh-cut produce association. Disponível em: http://www.creativew.com/ sites/ifpa/about.html. Acesso em: Io jun. 202I.

INSTITUTO ADOLFO LUTZ. Métodos químicos e físicos para análise de alimentos. 3. ed. São Paulo: IMESP, p. 27, 1985.

MODA, E. M., PILON, L., ZOCCHI, S. S., SPOTO, M. H. F. Qualidade físico-química e sensorial de abacaxi minimamente processado e irradiado. B. CEPPA, Curitiba v. 26, n. 2, jul-dez. 2008.

MORETTI, C.L. Manual de processamento mínimo de frutas e hortaliças..$^{\circ}$ ed. Brasília: Embrapa Hortaliças, 53ıp., 2007.

PRADO, M. E. T., VILAS-BOAS, E. V. de B., SANTOS, J. C. B., PINHEIRO, A. C. M., MATTOS, L. M., ARAÚJO, F. M. M., CHitARRA, A. B., OliVEIRA, E. C. M. Influência do hipoclorito de sódio sobre a qualidade de abacaxis minimamente processados. In: Encontro Nacional de processamento mínimo de frutas e hortaliças, 2., 200o, Viçosa. Resumos... Viçosa, MG: UFV, p. 5, 2000.

SANTOS, J. B. C, VILAS-BOAS, E. V. B., PRADO, M. E. T., PINHEIRO, A. C. M. Avaliação da qualidade do abacaxi "Pérola" minimamente processado armazenado sob atmosfera modificada. Ciência Agrotécnica, v. 29, n. 2, p. 353-361, 2005.

SARZI, B., DURIGAN, J. F. Avaliação física e química de produtos minimamente processados de abacaxi-Pérola. Rev. Bras. Frutic., Jaboticabal - SP, v. 24, n. 2, p. 333-337, agosto, 2002.

SIlVA, G. C., MAIA, G. A, FILHO, M. S. M. S., FIGUEIREDO, R. W. de, FILGUEIRAS, H. A. C., SOUZA, A. C. R. de. Efeito de diferentes concentrações de cloreto de cálcio na qualidade do abacaxi 'Pérola' minimamente processado. Revista Brasileira de Fruticultura, Jaboticabal - SP, v. 25, n. 2, p. 216-219, agosto, 2003.

SILVA, N. da, JUNQUEIRA, V., SILVEIRA, N. F. A., TANIWAKI, M. H., SANTOS, R. F. S. dos, GOMES, R. A. R. Manual de métodos de análise microbiológica de alimentos e água. 4 edição. São Paulo: Livraria Varela, 6ı4p, 2010.

TEIXEIRA, E., MEINERT, E., BARBETA, P. A. Análise Sensorial dos Alimentos. Florianópolis: Ed da UFSC,18op.1987.

THÉ, P. M. P. Efeitos da associação de tratamento hidrotérmico, cloreto de cálcio e atmosfera modificada sobre o escurecimento interno e qualidade do abacaxi cv. "SmoothCayenne". Lavras, 128 p. [Dissertação] (Mestrado em Ciência e Tecnologia de Alimentos) - Universidade Federal de Lavras, 200I. 
VANETTI, M. C. D. Segurança microbiológica em produtos minimamente processados. In: Encontro Nacional sobre processamento mínimo de frutas e hortaliças, 2004, Viçosa, MG. Anais... Viçosa: UFV, P.30-31, 2004. 